\title{
Preliminary research of water classification from TM images in Yangtze estuary
}

\author{
Kuang Runyuan ${ }^{1,2}$, Zhou yunxuan ${ }^{2}$, Shen \\ fang $^{2}$, Lixing ${ }^{3}$, Zhu yuanfeng ${ }^{1}$ \\ (1. School of Architectural and Surveying \& \\ Mapping Engineering, Jiangxi University of \\ Science and Technology, Ganzhou, China) \\ (2. State key Laboratory of Estuarine \&Coastal
}

\begin{abstract}
Classification of water body helps to understand relationships between different properties inside a certain class and quantify variations between different classes. The paper concentrates on studying classification of water in Yangtze estuary based on in site investigations of spectral reflectance properties and water color parameters. By our researching, we found eight optical classes of water bodies. We put forward an algorithm of reflectance spectrum slope in order to distinguish different spectrum reflectance types. The algorithms applied to water body classification of a TM image. From TM image, we detected six water classes. Spatial distributions of different water classes are consistent with the facts. The results of study are beneficial to monitor dynamic distributions of different water classes and provide a basis for regional algorithms to retrieve biogeochemical parameters concentrations.
\end{abstract}

Keywords: Yangtze estuary, water classification, spectrum slope, TM image

\section{Introduction}

Estuary is considered to one of hotspot areas about studying global change, because there are many exchange processes of matter and energy between land and ocean in the area. These processes effect estuarine ecological environment, such as water quality, delta growth and retreat, scouring and silting changes of river bed and harbor engineering ${ }^{[1,2]}$. However, people don't know much about change mechanism of environment in the estuary, due to high spatial and temporal dynamics in the estuary. Thus, only traditional in site measurements are inadequate in studies estuarine environment. For obtained firsthand large scale information about estuary,
Research, East China Normal University, Shanghai 200062, China)

(3. School of Geodesy and Geomatics, Xuzhou

Normal University, Xuzhou, China)

The correspondent author's email:

rykuang@163.com

remote sensing provides a good method with fine spatial resolution and high frequency measurement. Although obtaining some meaningful achievement ${ }^{[3]}$, quantitative interpretation of ocean color remote sensing image still face many challenging. On the one hand, atmospheric correction procedure in Open Ocean is failure in estuarine area ${ }^{[3]}$, on other hand quantitative inversion algorithmsis regional and non-portability for complex component and high variability of hydrodynamic processes in estuary ${ }^{[4]}$.In order to build a set of sophisticated algorithms, we need obtain prior knowledge of water optical component in the estuary. An alternative method of building inversion model in optical complex water is based on optical classification that aim at grouping water with similar optical characteristics and develop adapted algorithm for each water class. In this paper, in site measurement data and TM image were used for identify different optical water types in the Yangtze estuary. Water classification is important significance for spatial-temporal dynamic monitoring of different water mass and developing different algorithm for different water type in the Yangtze estuary.

\section{Methods}

Yangtze estuary is located in the eastern China. The estuary is characterized by the three-order bifurcations and four-branch channels discharging into the East China Sea. From 2007 to 2010, in situ measurements were carried out in the Yangtze estuary at different seasons and various tide conditions. Hyperspectral radiometric measurements were performed by above water surface method ${ }^{[5]}$. Water samples were simultaneously collected for the acquisition of water components concentrations from surface to bottom in vertical direction. Using in site data remote sensing reflectance was 
calculated by Tang ${ }^{[6]}$ proposed method. Kuang et al ${ }^{[7]}$ have analyzed characteristics of spectral remote sensing reflectance. The results show that there are eight types of remote sensing reflectance in Yangtze estuary. In order to distinguish different type of remote sensing reflectance, a representative data was chose respectively in each type of remote sensing reflectance. Eight types of remote sensing reflectance are plotted on Fig.1. Because of water components concentration effect, remote sensing reflectance presents the form of peak-valley with distinguish different water spectral reflectance.

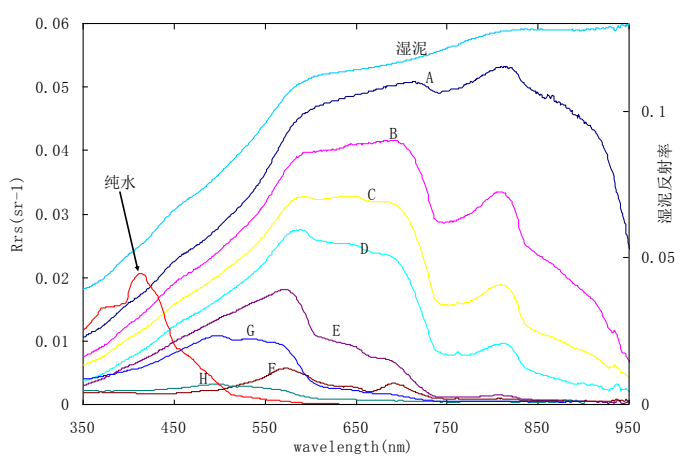

Fig. 1Remote sensing reflectance in Yangtze estuary

According to measured data in Yangtze estuary, the paper put forward an algorithm of spectrum slope in order to distinguish different spectrum types. The algorithmic formula can be expressed as follow.

$S=\frac{R_{i}-R_{j}}{\lambda_{i}-\lambda_{j}}$

Where $\mathrm{S}$ is spectrum slope, $\lambda_{i}, \lambda_{j}$ is different wavelength. $\mathrm{R}_{\mathrm{i}}$ and $R_{j}$ are remote sensing reflectance corresponding to wavelength $\lambda_{i}, \lambda_{j}$.There are two conditions of distinguish different spectrum types as follows.

(1)The size of single $S$ value: $S>0$, or $S<0$, or $S=0$;

(2)Compare of two sets of $S$ value: $S 1>S 2$, or $S 1<S 2$, or $\mathrm{S} 1=\mathrm{S} 2$.

In order to use spectrum slope algorithm on remote sensing images, the paper select Landsat/TM images. The four radiometric bands of TMin the Visual and Near Infraredregion are centered at 0.485um (0.45-0.52), 0.56um (0.52-0.6), 0.66um (0.63-0.69), 0.83um (0.76-0.9). Eight types of measured remote sensing reflectance corresponding to four radiometric bands are plotted on Fig. 2. In figure, spectrum slope value changes with wavelength and water components. We can know remote sensing reflectance type on the basis of judging of spectrum slope $S$ value.

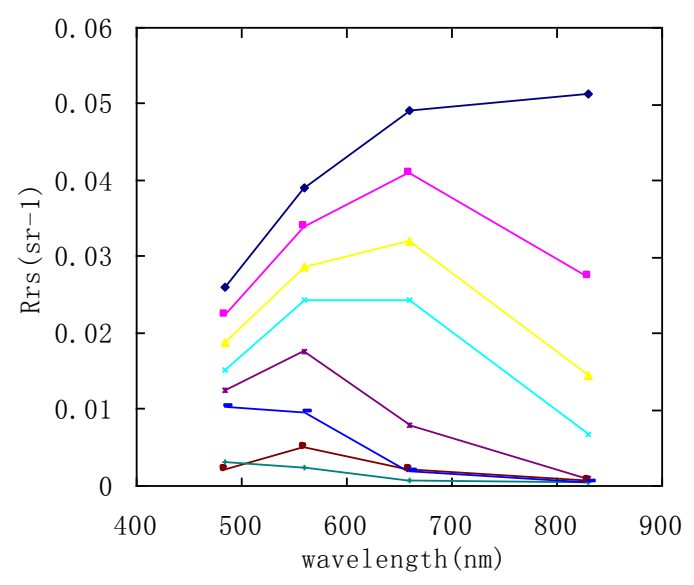

Fig. 2 Remote sensing reflectance corresponding to TM visual and near infrared band

Firstly, S values of each two from Red, Green, Blue band can distinguish between turbid water and clear water. Secondly, S values of adjacent band in short wavelength can distinguish between areas with high chlorophyll, areas with low chlorophyll, and areas with very clear water from clear water. Finally, turbid water can be distinguished between high turbid water, low turbid water from $\mathrm{S}$ value of Green, Red and Near Infrared, et al. algorithm process are as follows:

(1) $(\mathrm{R} 3-\mathrm{R} 4) /(\lambda 3-\lambda 4)<0,(\mathrm{R} 3-\mathrm{R} 4) /(\lambda 3-\lambda 4)<(\mathrm{R} 3-\mathrm{R} 1) /(\lambda 3-\lambda 1)$, denoted by $\mathrm{W}$, in site no measurement;

(2) $(\mathrm{R} 3-\mathrm{R} 4) /(\lambda 3-\lambda 4)<0,(\mathrm{R} 3-\mathrm{R} 4) /(\lambda 3-\lambda 4)>=(\mathrm{R} 3-\mathrm{R} 1) /(\lambda 3-\lambda 1)$, denoted by $\mathrm{H}$;

(3) $\quad(\mathrm{R} 3-\mathrm{R} 4) /(\lambda 3-\lambda 4)>=0, \quad(\mathrm{R} 4-\mathrm{R} 1) /(\lambda 4-\lambda 1)<0 \quad$,

$(\mathrm{R} 4-\mathrm{R} 1) /(\lambda 4-\lambda 1)<(\mathrm{R} 4-\mathrm{R} 2) /(\lambda 4-\lambda 2), \quad(\mathrm{R} 3-\mathrm{R} 1) /(\lambda 3-\lambda 1)>=0$, denoted by $\mathrm{F}$;

(4) $(\mathrm{R} 3-\mathrm{R} 4) /(\lambda 3-\lambda 4)>=0 \quad, \quad(\mathrm{R} 4-\mathrm{R} 1) /(\lambda 4-\lambda 1)<0 \quad$, $(\mathrm{R} 4-\mathrm{R} 1) /(\lambda 4-\lambda 1)<(\mathrm{R} 4-\mathrm{R} 2) /(\lambda 4-\lambda 2),(\mathrm{R} 3-\mathrm{R} 1) /(\lambda 3-\lambda 1)<0$, denoted by $\mathrm{G}$;
(5) (R3-
$\mathrm{R} 4) /(\lambda 3-\lambda 4)>=0$,
$(\mathrm{R} 4-\mathrm{R} 1) /(\lambda 4-\lambda 1)<0$, $(\mathrm{R} 4-\mathrm{R} 1) /(\lambda 4-\lambda 1)>=(\mathrm{R} 4-\mathrm{R} 2) /(\lambda 4-\lambda 2)$, denoted by $\mathrm{E}$;

(6) $\quad(\mathrm{R} 3-\mathrm{R} 4) /(\lambda 3-\lambda 4)>=0 \quad, \quad(\mathrm{R} 4-\mathrm{R} 1) /(\lambda 4-\lambda 1)>=0 \quad$, $(\mathrm{R} 4-\mathrm{R} 2) /(\lambda 4-\lambda 2)<=0, \quad|(\mathrm{R} 3-\mathrm{R} 1) /(\lambda 3-\lambda 1)|<|\quad(\mathrm{R} 1-\mathrm{R} 2) /(\lambda 1-\lambda 2)|$, denoted by $\mathrm{C}$ and $\mathrm{D}$;
(7)
$(\mathrm{R} 3-\mathrm{R} 4) /(\lambda 3-\lambda 4)>=0$,
$(\mathrm{R} 4-\mathrm{R} 1) /(\lambda 4-\lambda 1)>=0$,

$(\mathrm{R} 4-\mathrm{R} 2) /(\lambda 4-\lambda 2)<=0,|(\mathrm{R} 3-\mathrm{R} 1) /(\lambda 3-\lambda 1)|>=|(\mathrm{R} 1-\mathrm{R} 2) /(\lambda 1-\lambda 2)|$, denoted by B; 
$(\mathrm{R} 4-\mathrm{R} 2) /(\lambda 4-\lambda 2)>0$, denoted by $\mathrm{A}$;

\section{Results}

The Landsat Thematic Mapper(TM) image on 13 March 2001 was used in the paper. In order to eliminate atmosphere effect, the atmospheric radiance was removed by using FLAASH methods in ENVI. After atmosphere correction, water body was classified by use of spectrum slope algorithm in the Landsat TM image. The results showed that water in Yangtze River estuary was classified six types on 13 March 2001, as shown in Fig. 3. W and F water types weren't detected. From the diagram, we also know spatial distribution of different type's water body is very law. Class A is mainly distributed in north branch of Yangtze estuary, water nearby beach (ChongmingDongtan, Jiuduansha Dong, Nanhuinearshore, et al).Class B is distributed in main branch of Yangtze estuary (south branch, north channel, south channel, north and south passage) and eastern contiguous area of beach(turbidity maximum zone).Class $\mathrm{C} / \mathrm{D}$ is mainly distributed in upstream of Yangtze estuary and eastern area of class B in area off Yangtze estuary. Water type distribution from west to east off Yangtze Riverestuary is in the order of class $\mathrm{C} / \mathrm{D}$, class $\mathrm{E}$ and class G.Class Hrandomly distributed in the class $\mathrm{G}$.

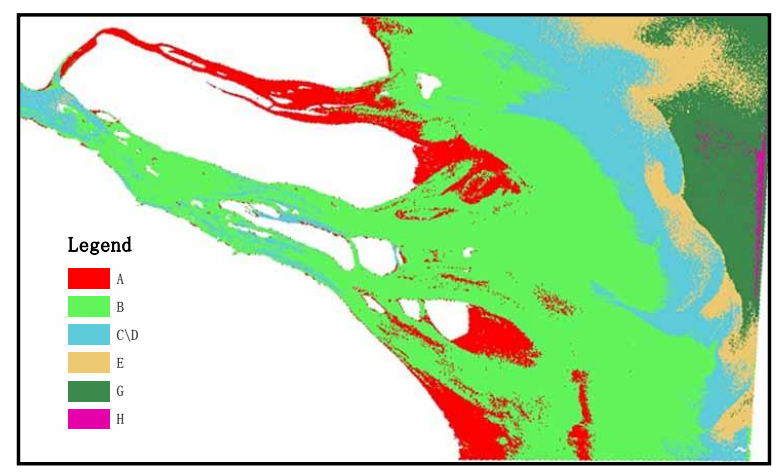

a. TM image classification

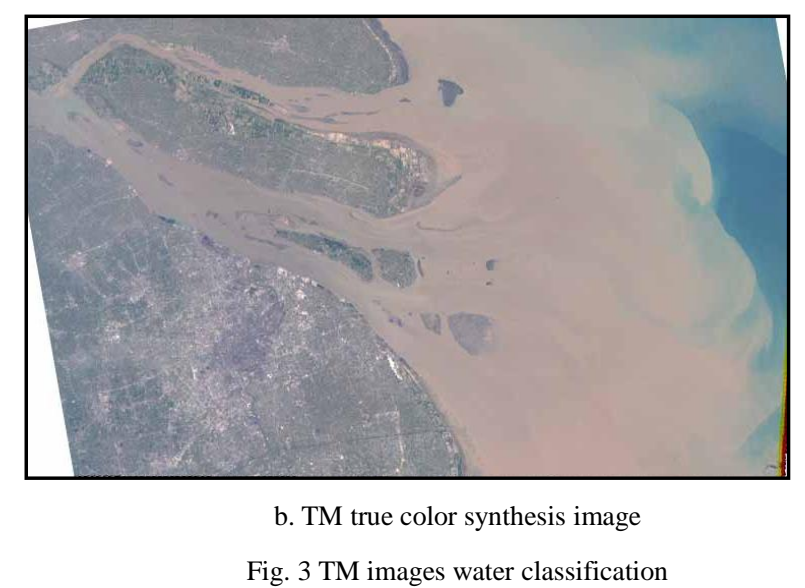

The spatial distribution characteristics of different water class show water optical difference in spatial distribution which is closely related to biogeochemical parameters in water, such as suspended sediment, chlorophyll, and CDOM (color dissolved organic matter). According to previous studies ${ }^{[7]}$, suspended sediment and CDOM are predominant among water component inside Yangtze estuary. However, CDOM and chlorophyll are major component in an area off Yangtze estuary. From upstream to off Yangtze estuary, suspended sediment gradually deposited under runoff and tide current. Suspended sediment presents a definite pattern of distribution. By our survey, SSC (suspended sediment concentration) of class A reach to beyond $0.5 \mathrm{~g} / \mathrm{l}$, SSC of class $B$ is between $0.14 \mathrm{~g} / 1$ and $0.55 \mathrm{~g} / 1, \mathrm{SSC}$ of class C/D is between $0.05 \mathrm{~g} / \mathrm{l}$ and $0.26 \mathrm{~g} / \mathrm{l}, \mathrm{SSC}$ of class $\mathrm{E}$ is about between $0.0075 \mathrm{~g} / \mathrm{l}$ and $0.105 \mathrm{~g} / 1$, SSC of class $\mathrm{G}$ is about between $0.005 \mathrm{~g} / 1$ and $0.02 \mathrm{~g} / \mathrm{l}, \mathrm{SSC}$ of class $\mathrm{H}$ is about between $0.001 \mathrm{~g} / \mathrm{l}$ and $0.01 \mathrm{~g} / \mathrm{l}$. chlorophyll concentration is very low, general below $10 \times$ $10^{-3} \mathrm{~g} / \mathrm{l}$ except class $\mathrm{F}$ (beyond $10 \times 10^{-3} \mathrm{~g} / \mathrm{l}$ ).

\section{Conclusions}

By investigate water optical properties and biogeochemical parameters, the estuary water can be classified relying on the concentrations of optically active substances, such as suspended sediment, chlorophyll, and CDOM. Based on analysis of the shapes of reflectance spectra measured in the Yangtze estuary, the paper put forward an algorithm of reflectance spectrum slopes which can distinguish different optical classes of water bodies in the Yangtze estuary. The algorithm applied to water classes of a TM image. The classification results are basically consistent with facts. The water classification in Yangtze estuaryishelpful to build up 
retrieval regional models for different water class area.

The paper preliminarily shows the feasibility of an algorithm of spectrum reflectance slope which distinguish different water classes. But it should be noted that in the present paper the optical properties considered only water spectrum reflectance and the algorithm applied only to a TM image. The results also exist disadvantages. In order to build up a sophisticated algorithm, we must develop many optical investigations in the future.

\section{Acknowledgments}

This study was supported by National Natural Science Foundation of China (No.41101322), by Jiangxi Provincial Department of Science and Technology (No. 20114BAB213022), by science and technology projectof Jiangxi Provincial Education Department (No.GJJ13424), by Doctor's Fund at Jiangxi University of Science and Technology (No. 22018).

\section{References}

[1] Che Y., He Q., Wu E. N. Study of heavy metals influenced by sediment resuspension in the ChangJiang estuary. Resources and Environment in the Yangtze Basin, 2003, 12 (5): 440-444.

[2] Zhang G.A.,Yu Z.Y., He Q., et al. Primary analysis of sediment motion before and after the first phase engineering of the deep waterways in Changjiang estuary. Journal of Sediment Research
(Chinese),2003 (6): 31-38.

[3]IOCCG, 2000. Remote Sensing Ocean Colour in Coastal, and OtherOptically-Complex Waters. In: Sathyendranath, S. (Ed.), Reportsof the International Ocean-Colour Coordinating Croup,No. 3 IOCCG, Dartmouth, Canada.

[4]Liu Z. G., Zhou Y. X., Shen F. Statistical analysis of suspended sediment concentration in offshore waters based on field measurement of reflectance hyper-spectral. Journal of Hydraulic Engineering, 2007, 38(7): 799-805.

[5]Fargion G.S, Mueller J.L. Ocean Optics Protocols for Satellite Ocean Color Sensor Validation, Revision-4, NASA/TM-2003.

[6]Tang, J.W., Tian, G.L., Wang, X.Y., et al. The Methods of Water Spectra Measurement and Analysis I :Above-Water Method. Journal of Remote Sensing (Chinese), 2004, 8(1):37-44.

[7]Kuang R. Y. Remote sensing model of ocean colour parameters in Yangtze estuary. Doctoral dissertation, 2010: East China Normal University. 